\title{
Sorptive properties of modified maize starch as indicators of their quality**
}

\author{
Aneta Ocieczek ${ }^{1 *}$, Magdalena Skotnicka ${ }^{2}$, and Kinga Baranowska ${ }^{1}$ \\ ${ }^{1}$ Department of Commodity Science and Quality Management, Gdynia Maritime University, Morska 83, 81-225 Gdynia, Poland \\ ${ }^{2}$ Department of Food Commodity Science, Medical University of Gdańsk, Dębinki 7, 80-211 Gdańsk, Poland
}

Received October 25, 2016; accepted June 12, 2017

\begin{abstract}
A b s t r a c t. The physical and adsorptive properties of three products of modified maize starch in terms of the susceptibility of starch granules to surface processes as affected by their physicochemical diversity was compared in this study, using five mathematical models. It was assumed that modification of native starch is an important factor affecting its adsorptive properties. The products under study differed significantly in terms of the distribution of the size and shape parameters of their granules. The Guggenheim, Anderson and de Boer equation, characterised by relatively low sums of square deviations and low and similar errors of their different parameters, was the most useful in the description of empirically determined isotherms of adsorption. Parameters of the Guggenheim, Anderson and de Boer equation were used to estimate the parameters of the product surface microstructure. Modification of native maize starch differentiated the size of the monolayer, specific surface of sorption, and characteristics of capillaries.

$\mathrm{K}$ e y w o r d s: modified maize starch, BET, GAB, Lewicki equations (1998, 2000), Peleg
\end{abstract}

\section{INTRODUCTION}

The demand for starch is constantly growing, which is reflected by its EU production increase from 16 to $36 \mathrm{mln} \mathrm{t}$ over the last few years. Although many types of starch are available on the market, maize, potato and wheat starches, differing in their chemical composition, shape and size of granules, have the largest share in the global production (Fuglie, 2004). The major starch producers in the European Union are Germany, Denmark and Sweden. On the other hand, the largest maize starch producer is Spain, as the weather conditions of this country are particularly favourable for maize cultivation. Starches that are most frequently

\footnotetext{
*Corresponding author e-mail: a.ocieczek@wpit.am.gdynia.pl

**This work was financed from the subsidy 396/DS/2015.
}

used in the industry include maize and potato starch, while starches made from wheat, tapioca and rice are used less often (Kosseva and Webb, 2013).

Industrial application of natural starch is limited due to its specific properties which include water insolubility and a tendency for easy retrogradation and syneresis. Starch modification reduces its tendency to retrograde, the tendency of gelatinisation of pastas or gel syneresis (Tharanathan, 2005). It also improves the clarity and sheen of pastas, the texture of gels and the ability to form films, and their adhesion (Visakh, 2015). Another purpose of starch modification is to stabilise its granules during processing and to facilitate its various applications in industry and food production (Visakh, 2015). The interest in starch and in modified starch is growing as a result of the progress in its processing technology and discovering new applications for starch (Hebelstrup et al., 2015). Currently conducted studies on starch modifications are aimed at obtaining new, currently unknown properties and uses of this material.

Usable properties of starch can be modified by the application of physical, chemical, enzymatic, biotechnological (genetic) and combined modification methods (Ashogbon and Akintayo, 2014).

Physically modified starches are usually characterised by a lowered pasting temperature and some of them display cold-swelling ability, while others become resistant to acidic environment and very quickly dissolve in hot water. They are used for preparing cold milk desserts, fruitflavoured starch jellies, sauces, milk drinks and in cottage

(C) 2017 Institute of Agrophysics, Polish Academy of Sciences 
cheese production. Starch modified by complexing with fat at a high temperature and pressure can be used as a fat substitute in ice cream.

Physically modified starches are not treated as food additives, but they are classified as foodstuff, just like natural starch (Leszczyński, 2004).

The following studies have been carried out recently on new methods of physical modification of starches originating from various sources: starch superheating (Steeneken and Woortman, 2009); iterated syneresis (Lewandowicz and Soral-Śmietana, 2004); thermally-inhibited processing (dry heating) (Lim et al., 2002); osmotic pressure treatment (Pkkahuta et al., 2007); multiple deep-freezing and thawing (Szymońska et al., 2003); instantaneous controlled pressure drop (Zarguili et al., 2006). Modification of starch properties can also be achieved as a result of mechanical activation by ball milling (Huang et al., 2007); micronisation in a vacuum ball mill (Che et al., 2007); pulsed electric field treatment (Han et al., 2009); or corona electrical discharge treatment (Nemtanu and Minea 2006).

Another type of modification applied to starches is enzymatic modification. This type of modification consists in treating starch suspensions with enzymes, including hydrolysing enzymes, which leads to obtaining derivatives with very advantageous utility features. This technique dates back to when the demand for glucose syrup or maize syrup with high fructose content first emerged (Neelam et al., 2012). Enzymatic transformations are carried out in order to obtain products of hydrolysis such as maltodextrins or syrups. Those transformations are the most important aims for starch processing. However, such processes cannot be regarded as modifications in the precise meaning of this term, since the high-molecular character of the transformation products is not preserved. Treatment of maize starch with $\beta$-amylase, $\beta$-amylase and transglucosydase, maltogenic $\alpha$-amylase and maltogenic $\alpha$-amylase with transglucosydase, results in a significant reduction in digestion time by $14.5,29.0,19.8$, and $31.0 \%$, respectively, and in the production of resistant starch characterised by reduced glycemic index, which may be used, in particular, in the diet of persons with pre-diabetes, diabetes, and in cardiovascular diseases and obesity. It is assumed that an increase in the density and degree of arrangement of starch crystalline structure after the modification process contributes to slowing the digestion (Ao et al., 2007).

On the other hand, chemical modification consists in the replacement of hydroxyl groups present in anhydroglucose rings as a result of oxidation, esterification or etherification. None of these processes change the supramolecular structure of granules, but they change the structure of starch macromolecules. This results in significant changes in the physicochemical properties of starches in water solutions due to the change of interactions between a polymer and a solvent. Chemically-modified starches are obtained as a result of treating natural starch with various chemical compounds (Alcázar-Alay and Meireles, 2015). Chemical modification strongly affects gelatinisation (pasting) ability, the formation of pastas and the retrogradation of starch originating from various botanical sources. The chemical modification of starch is a constant process since there are many possibilities of its implementation. New preparations with new useful qualities resulting from introduced changes continue to emerge in the market (Ashogbon and Akintayo, 2014). Chemical and utility properties obtained as a result of starch modification are determined, among others, by the source of starch, reaction conditions (reagent concentration, $\mathrm{pH}$, reaction time and the presence of a catalyst), type of substituent, substitution degree as well as the distribution of substituents in a starch molecule (Hirsch and Kokini, 2002; Wang and Wang, 2002). Starch modification is usually obtained through derivatisation, such as acetylation, cationisation, oxidation, acid hydrolysis or cross-linking. However, the possibilities of using these techniques are limited due to problems related to consumer and environmental safety. Therefore, new tendencies have emerged, known as a double modification, which consist in combining physical and chemical methods, e.g. microwave-assisted acetylation or HHP-aided phosphorylation (Alcázar-Alay and Meireles, 2015).

Genetic modification includes a set of transgenic technologies consisting in the application of enzymes involved in starch biosynthesis. In this way, it is possible to obtain a product with an advantage over products acquired through environmentally hazardous modifications using chemical substances, performed on starch after its collection, or enzymatic modifications. Genetic modifications can be carried out using traditional farming techniques or biotechnology. By using the genetic modification method, it is possible to obtain amylose-free starch or starch with a high amylose content (Neelam et al., 2012).

Modified starches are used in various branches of industry. In the food industry, they are used as foodstuffs, fillers, thickeners, gelling and texture-forming products, aromas, microcapsules, dietary fibre, as well as components of low-calorie food (Alcázar-Alay and Meireles, 2015; Jobling, 2004).

In the paper industry, modified starches are also used as fillers, agents accelerating the dehydration of paper pulp, increasing paper strength, improving paper surface, coating the paper with pigment mixtures by binding pigments and regulating viscosity and rheological properties of mixtures, or glues binding paper fibres. In the textile industry, modified starches are commonly used as adhesives for warps (buckram) and auxiliary agents used in the finishing and the dying process. The cosmetic industry adds starch and its derivatives to powders, dusting-powders and as carriers of colour and fragrance. Modified starch is also used for biodegradable detergents, cream thickeners and components of ointments and conditioners (Alcázar-Alay and Meireles, 2015; Jobling, 2004). 
The aim of this research was to compare the adsorptive properties of modified starches produced from waxy maize: C*Tex - Instant 12616, C*PolarTex - Instant 12650, C*PolarTex 06748 in the ability of their surface to interact with water vapour, and to present comparative characteristics using mathematical sorption models.

To achieve this aim, the following general research hypothesis was formulated, which assumed that the result of native starch modification is a significant factor determining a change in adsorption properties.

\section{MATERIALS AND METHODS}

The research material consisted of three types of modified starches produced from waxy maize:

$\mathrm{C}^{*}$ Tex - Instant 12616 - pregelatinised, stabilised and cross-linked waxy maize starch. Package labelling: pregelatinised acetylated distarch adipate. Product classification: CN Code (Valid for UE 28) 350510 50; E No - E 1422, Country of origin: Germany, Netherlands.

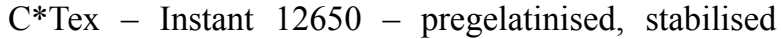
and cross-linked waxy maize starch. Package labelling: pregelatinised hydroxypropyl distarch phosphate. Product classification: CN Code (Valid for UE 28) 350510 50; E No - E 1442, Country of origin: Netherlands.

C*PolarTex 06748 - stabilised and highly cross-linked waxy maize starch. Package labelling: hydroxypropyl distarch phosphate. Product classification: CN Code (Valid for UE 28) 350510 50; E No - E 1422, Country of origin: Netherlands, USA.

The distribution of the size and shape of particles in samples of the powders under study was examined with a Morphology G3 automatic analyser, manufactured by Malvern Instruments, which measures granulometric distribution of particles with sizes ranging from 0.5 to $1000 \mu \mathrm{m}$. The numerical distributions of the following were estimated: diameter, circularity, convexity, elongation, aspect ratio and solidity.

The determination of water content was carried out in accordance with PN-ISO 712:2012 standard for cereals and cereal products.

Water activity was evaluated in the AquaLab apparatus (Series 3, TE model, Decagon Devices, Inc., Pullman, WA, USA) with an accuracy of \pm 0.003 at $293.15 \mathrm{~K}$.

The adsorption isotherms were determined with the static-desiccator method. This method was based on the evaluation of humidity balance between a tested sample and the atmosphere with a given relative humidity regulated by saturated salt solutions: $\mathrm{NaOH} a_{w}=0.070 ; \mathrm{LiCl}$ $a_{w}=0.111 ; \mathrm{CH}_{3} \mathrm{COOK} a_{w}=0.231 ; \mathrm{MgCl}_{2} a_{w}=0.330 ; \mathrm{K}_{2} \mathrm{CO}_{3}$ $a_{w}=0.440 ; \mathrm{Na}_{2} \mathrm{Cr}_{2} \mathrm{O}_{7} a_{w}=0.548 ; \mathrm{KJ} a_{w}=0.699 ; \mathrm{NaCl} a_{w}=$ $0.754 ; \mathrm{KCl} a_{w}=0.851 ; \mathrm{KNO}_{3} a_{w}=0.932 ; \mathrm{K}_{2} \mathrm{Cr}_{2} \mathrm{O}_{7} a_{w}=0.979$ (Ocieczek, 2010). Each point of adsorption isotherm was the arithmetic average of five repetitions.
The scope of studies included water activity from 0.07 to 0.98 . The temperature was $293.15 \mathrm{~K}\left(20^{\circ} \mathrm{C}\right)$. The balance of configuration settled 50 days after the samples were placed in a desiccator. Thymol was placed in the desiccators with water activity $>0.7$ in order to protect the samples against the growth of microorganisms.

The individual starch samples of approx. $1 \mathrm{~g} \pm 0.1 \mathrm{mg}$, designated for the determination of adsorption isotherms in the first stage of the experiment, were placed in $35 \mathrm{~mm}$ diameter weighing vessels in order to uniformly cover the whole surface of a vessel. In the next step, the vessels were placed in a desiccator containing $\mathrm{P}_{2} \mathrm{O}_{5}$ as a drying compound, at room temperature, for 3 weeks in order to minimise humidity $(\sim 2 \%)$ in the tested samples. Following a 3-week period, the samples were weighed and placed in the desiccators with a saturated solution.

The equilibrium water content was calculated and adsorption isotherms were drawn with the use of MS Excel based on the initial mass of product (determined after 3-week incubation in the desiccator with $\mathrm{P}_{2} \mathrm{O}_{5}$ ) and the changes of water content.

The measurements of water activity 50 days after placing the samples in the desiccators were carried out with AquaLab (Series 3, TE model, Decagon Devices, Inc., Pullman, WA, USA) with an accuracy of \pm 0.003 at $293.15 \mathrm{~K}\left(20^{\circ} \mathrm{C}\right)$.

The diversification of the course of sorption isotherms across the entire $a_{w}$ range was statistically analysed using Student $t$-test for differences between the means of matched pairs, regarding differences as statistically significant at a significance level not exceeding $\mathrm{p}=0.01$.

The empirical results of the studied adsorption phenomena were described by:

BET equation of the form:

$$
v=\frac{v_{m} \mathrm{C} a_{w}}{\left(1-a_{w}\right)\left[1+(\mathrm{C}-1) a_{w}\right]},
$$

where: $a_{w}$ - water activity, $v$ - equilibrium water content ( $\mathrm{g} \mathrm{H}_{2} \mathrm{O}\left(100 \mathrm{~g}^{-1}\right.$ d.m. $\left.)\right), v_{m}$ - water content in the monolayer $\left(\mathrm{g} \mathrm{H}_{2} \mathrm{O}\left(100 \mathrm{~g}^{-1}\right.\right.$ d.m.) $), \mathrm{C}$ - energy constant (Figura and Teixeira, 2007; Paderewski, 1999; Pałacha and Sitkiewicz, 2010).

$\mathrm{GAB}$ equation of the form:

$$
v=\frac{v_{m} \mathrm{C}_{\mathrm{G}} \mathrm{K} a_{w}}{\left(1-\mathrm{K} a_{w}\right)\left(1-\mathrm{K} a_{w}+\mathrm{C}_{\mathrm{G}} \mathrm{K} a_{w}\right)},
$$

where: $\mathrm{C}_{\mathrm{G}}$ - energy constant of Guggenheim, $\mathrm{K}$ - constant correcting properties of multilayer molecules in relation to the liquid phase (Figura and Teixeira, 2007; Paderewski, 1999; Pałacha and Sitkiewicz, 2010).

The equation of Lewicki (1998), in the form:

$$
v=\frac{\mathrm{F}}{\left(1-a_{w}\right)}-\frac{\mathrm{F}}{1+a_{w}^{\mathrm{H}}},
$$


where: F, G and H - constants (Lewicki, 1998; Pałacha and Sitkiewicz, 2010).

The equation of Lewicki (2000), in the form:

$$
v=A\left[\frac{1}{a_{w}}-1\right]^{\mathrm{B}-1}-1,
$$

where: A and B - constants (Lewicki, 2000; Figura and Teixeira, 2007).

Peleg requation in the form:

$$
v=A a_{w}^{\mathrm{B}}+D a_{w}^{\mathrm{E}},
$$

where: E - constants (Figura and Teixeira, 2007; Paderewski, 1999; Pałacha and Sitkiewicz, 2010).

The parameters of the equations used as the basis for the mathematical description of sorption isotherms were determined on the basis of empirical data. The identification was carried out using non-linear regression with a Monte Carlo algorithm. Such an approach prevents inhibition of the estimation process by a local minimum. Minimisation of the residual sum of squares was adopted as the target function (Ocieczek and Kostek, 2009). Calculations were performed in Excel 2007 and errors of the determined parameters of the BET GAB, Lewicki $(1998,2000)$ and Peleg equations were estimated using the SolverAid macro command which provides estimates of uncertainty (standard deviation, matrix of covariance and matrix of linear coefficients of correlation) of the parameter values obtained with the Solver.

\section{RESULTS AND DISCUSSION}

Morphological characteristics of starches from different plant sources vary with the genotype and cultural practices (Singh et al., 2003). The size of the starch granule has an important influence on the functional application of some native starches (Builders and Arhewoh, 2016). The values of diameters for native maize starch particles were equal to $5.8 \mu \mathrm{m}$ (Stasiak et al., 2013). The shape coefficient of native maize starches was approximately 1.1 (Stasiak et al., 2013). These results corroborate the results of earlier investigations that native maize starch granules are angular, spherical and lenticular-shaped (Singh et al., 2003).

Modification of native maize starch resulted in differences in some physical characteristics of the obtained powders (Table 1).

The powders under study were significantly different in terms of their particle size distribution. The distribution of particle diameter for hydroxypropyl distarch phosphate (product 06748) was close to normal, which was reflected in the smallest span between the minimal and maximal value and a relatively small standard deviation from the mean diameter of a particle. On the other hand, the distribution of the particle size of the other two preparations, pre-gelatinised acetylated distarch adipate (product 12616) and pre-gelatinised hydroxypropyl distarch phosphate (product 12650) significantly deviated from normal, which was reflected in a large span and a relatively large standard deviation from the mean diameter of a particle. A similar size distribution of modified waxy starches was observed by Bayod et al. (2008) and Juszczak et al. (2013).

Although all of the products can be regarded as polydispersive systems (particles of various diameters), product 06748 can be regarded as monomodal (the smallest differences between particle diameters) as opposed to the other, multimodal products (12616 and 12650) with great differences between the particle differences. An analysis of the numerical distribution of circularity shows that particles in product 06748 had a regular shape, close to a square $(0.838 \pm 0.175)$, and particles of the others resembled a rectangle (12616 - $0.587 \pm 0.249 ; 12650-0.551 \pm 0.252)$. Since particles of product 06748 had greater convexity than those of the other two products, therefore particles of product 06748 had much smaller elongation compared to the other two. In consequence, the mean coefficient of particle shape for product 06748 was significantly greater $(\sim 0.8)$ than for the other two ( 0.6). According to Singh et al. (2003), maize starch granules, just like rice and wheat starch granules, are less smooth-surfaced than potato starch granules.

The last aspect under analysis was the distribution of solidity of particles, whose mean value was medium for product 06748 compared to the other two, while its standard deviation was smaller, which indicates the stability of the feature for particles of product 06748 . In conclusion, modification which involved substituents in rings of native starch affects the physical properties of starch to a lesser extent than pre-gelatinising its granules, which modifies their physical properties significantly. Particles of pregelatinised preparations have diverse size and irregular shapes, which is reflected in their polydispersivity combined with multimodality. Similar conclusions were drawn by Lee et al. (2015).

Adsorptive properties of powders are a function of interactions between the surface of a body and water in capillaries, concentration of water vapour in capillaries, but mainly of the amount of water in the product (Dabrowski, 2001). Water is an important component of almost all food products and plays a crucial role in determining their physical properties as well as their microbiological, chemical and biochemical tendency to degrade (Figura and Teixeira, 2007). Therefore, a basic test to evaluate the sorption properties of selected modified starch preparations involves determination of water content in the examined material (Table 2).

The highest water content per dry matter was found for product 06748 , and the lowest for 12650 . In comparison to the data provided in the Certificates of Analysis and Compliance issued by the manufacturer, it can be claimed that the results obtained correlate with those data, while 
T a b l e 1. Selected physical characteristics of the tested preparations of modified starch

\begin{tabular}{|c|c|c|c|c|c|c|}
\hline \multirow{2}{*}{$\begin{array}{l}\text { Number } \\
\text { distribution }\end{array}$} & \multicolumn{6}{|c|}{ Parameter } \\
\hline & Min & $\operatorname{Max}$ & Mean \pm SD & $\mathrm{D}(\mathrm{n}, 0.1)$ & $\mathrm{D}(\mathrm{n}, 0.5)$ & $\mathrm{D}(\mathrm{n}, 0.9)$ \\
\hline \multicolumn{7}{|c|}{$12616($ particles counted $n=173448)$} \\
\hline Diameter $(\mu \mathrm{m})$ & 1.09 & 240.65 & $12.89 \pm 15.73$ & 1.71 & 8.23 & 28.16 \\
\hline Circularity & 0.003 & 1.000 & $0.587 \pm 0.249$ & 0.216 & 0.620 & 0.900 \\
\hline Convexity & 0.310 & 1.000 & $0.933 \pm 0.101$ & 0.752 & 0.964 & 0.994 \\
\hline Elongation & 0.000 & 0.952 & $0.406 \pm 0.201$ & 0.138 & 0.400 & 0.678 \\
\hline Aspect ratio & 0.048 & 1.000 & $0.594 \pm 0.201$ & 0.319 & 0.597 & 0.858 \\
\hline Solidity & 0.102 & 1.000 & $0.881 \pm 0.154$ & 0.613 & 0.914 & 0.988 \\
\hline \multicolumn{7}{|c|}{$12650($ particles counted $n=153680)$} \\
\hline Diameter $(\mu \mathrm{m})$ & 1.09 & 375.93 & $11.09 \pm 13.68$ & 1.59 & 6.45 & 25.55 \\
\hline Circularity & 0.005 & 1.000 & $0.551 \pm 0.252$ & 0.189 & 0.573 & 0.872 \\
\hline Convexity & 0.287 & 1.000 & $0.932 \pm 0.103$ & 0.744 & 0.963 & 0.994 \\
\hline Elongation & 0.000 & 0.963 & $0.440 \pm 0.203$ & 0.164 & 0.439 & 0.712 \\
\hline Aspect ratio & 0.037 & 1.000 & $0.560 \pm 0.203$ & 0.286 & 0.558 & 0.831 \\
\hline Solidity & 0.095 & 1.000 & $0.868 \pm 0.168$ & 0.563 & 0.898 & 0.985 \\
\hline \multicolumn{7}{|c|}{$06748($ particles counted $n=208039)$} \\
\hline Diameter $(\mu \mathrm{m})$ & 1.09 & 166.46 & $14.18 \pm 7.18$ & 6.93 & 12.73 & 22.56 \\
\hline Circularity & 0.001 & 1.000 & $0.838 \pm 0.175$ & 0.559 & 0.919 & 0.977 \\
\hline Convexity & 0.171 & 1.000 & $0.970 \pm 0.057$ & 0.870 & 0.983 & 0.997 \\
\hline Elongation & 0.000 & 0.950 & $0.216 \pm 0.146$ & 0.055 & 0.180 & 0.434 \\
\hline Aspect ratio & 0.050 & 1.000 & $0.784 \pm 0.146$ & 0.564 & 0.818 & 0.942 \\
\hline Solidity & 0.215 & 1.000 & $0.959 \pm 0.070$ & 0.838 & 0.982 & 0.998 \\
\hline
\end{tabular}

$\mathrm{D}(\mathrm{n}, 0.1)-10 \%$ of the particles are smaller than this diameter; $\mathrm{D}(\mathrm{n}, 0.5)$ - half of the particles are smaller than this diameter, half are longer than this diameter; $\mathrm{D}(\mathrm{n}, 0.9)-90 \%$ of the particles are smaller than this diameter.

T a b l e 2. Content and water activity of the tested preparations of modified starch

\begin{tabular}{ccccc}
\hline Product & $\begin{array}{c}\text { Water content } \\
\left(\mathrm{g} \mathrm{H}_{2} \mathrm{O}\right. \\
\left.\left(100 \mathrm{~g}^{-1} \mathrm{~d} . \mathrm{m} .\right)\right)\end{array}$ & $\mathrm{SD}$ & $\begin{array}{c}\text { Water } \\
\text { activity }\end{array}$ & $\mathrm{SD}$ \\
\hline 12616 & 5.931 & 0.097 & 0.225 & 0.001 \\
12650 & 4.680 & 0.054 & 0.187 & 0.003 \\
06748 & 15.270 & 0.116 & 0.511 & 0.004 \\
\hline
\end{tabular}

$\mathrm{SD}$ - standard deviation. the levels of water content empirically determined for products 12616 and 12650 are within the water content range declared by the producer.

Higher levels of water content corresponded to higher values of water activity, which is related to the dominant role of water content in modelling the function of water activity (Dąbrowski, 2001).

Isotherms of food product adsorption usually have a sigmoid shape (Andrade et al., 2011), which is also proven by the results of this study (Fig. 1). 


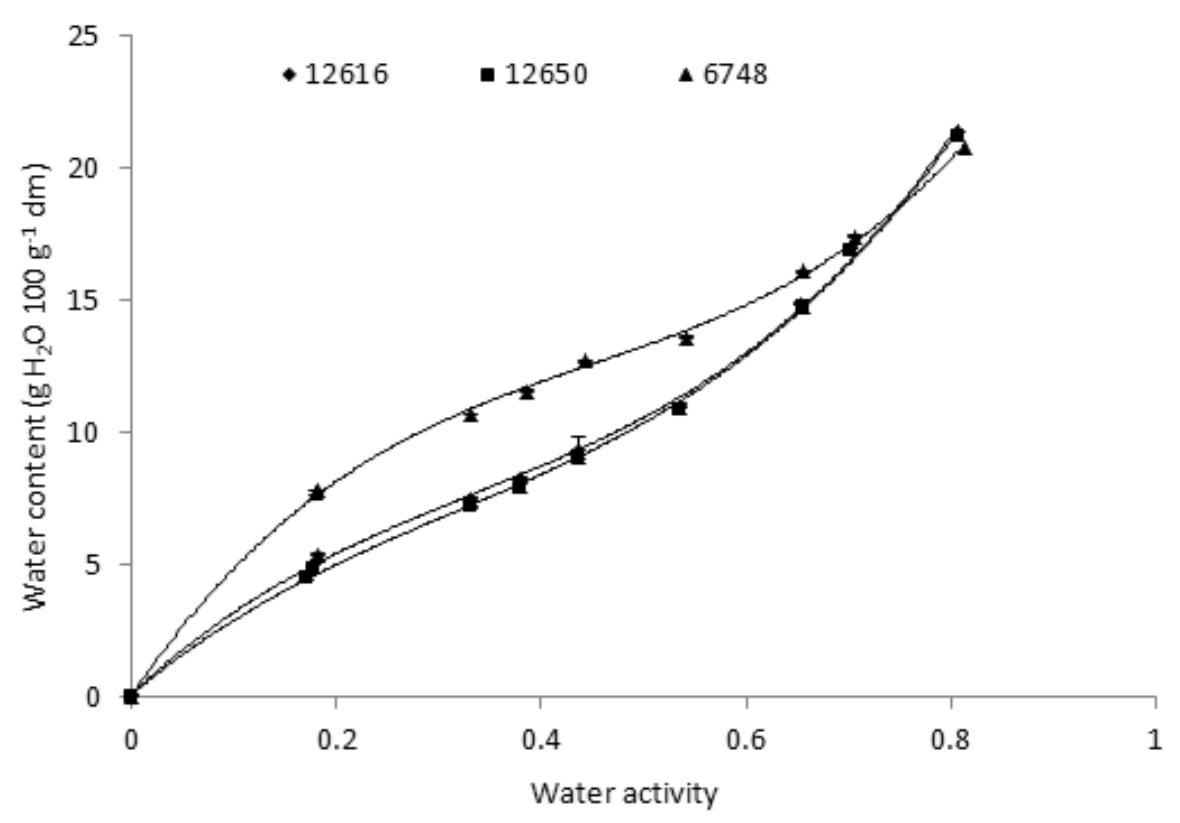

Fig. 1. Adsorption isotherms of water vapour by three types of modified maize starch at $20^{\circ} \mathrm{C}$.

T a b l e 3. Parameters of GAB equation and water activity values corresponding to monolayer covering determined for modified maize starch

\begin{tabular}{lccc}
\hline & \multicolumn{2}{c}{ Product } \\
\cline { 2 - 3 } Parameters & 12616 & 12650 & 06748 \\
\hline Sum of squared deviations $(\mathrm{SD})$ & $0.741 \pm 0.351$ & $0.724 \pm 0.347$ & $0.539 \pm 0.299$ \\
Water content in monolayer $\left(v_{m}\right)\left(\mathrm{g} \mathrm{H} \mathrm{O}^{\mathrm{O}}\left(100 \mathrm{~g}^{-1} \mathrm{~d} . \mathrm{m}.\right)\right)$ & $7.124 \pm 0.413$ & $7.440 \pm 0.498$ & $9.848 \pm 0.470$ \\
$\begin{array}{l}\text { Constant correcting properties of multilayer molecules in } \\
\text { relation to liquid phase }(\mathrm{K})\end{array}$ & $0.851 \pm 0.021$ & $0.839 \pm 0.023$ & $0.668 \pm 0.025$ \\
$\begin{array}{l}\text { Energy constant of Guggenheim }(\mathrm{C}) \\
\text { Water activity }\left(a_{w}\right)\end{array}$ & $8.432 \pm 1.629$ & $6.249 \pm 1.095$ & $17.265 \pm 2.862$ \\
& 0.301 & 0.340 & 0.290 \\
\hline
\end{tabular}

In order to verify the assumptions on the existence of significant differences in the course of adsorption isotherms of water vapour on the surface of the test samples of starch, which was conditional on the modification of native material, values of Student t-test were calculated for the differences between the means of matched pairs, stating that isotherms of all samples were characterised by diverse cour$\operatorname{se}\left(\mathrm{t}_{0.01}=3.169 ; \mathrm{t}_{12616 / 12650}=4.294 ; \mathrm{t}_{12616 / 06748}=4.466 ; \mathrm{t}_{12650 / 06748}=4.702\right)$.

All determined isotherms were characterised by continuity across the entire range of water activity, which may prove that starch modification did not give it an amorphous shape (Fox and McSweeney, 2003). The shape and the course of water adsorption isotherms of the same substance can significantly differ depending on the technological treatment applied or an addition of another component with water binding capacity (e.g. glucose, sucrose, sodium chloride, glycerol, etc.) (Skic and Sokołowska, 2015).

Water content corresponding to the monomolecular layer capacity is both the minimum and the optimum water content and does not result in quick hydrolytic or oxidative deterioration when left in the product. Knowledge of monolayer capacity also optimises costs in technological food processes, as it is also possible to accurately describe the final point of the material drying process (Gal, 1983).

The obtained results demonstrate that the parameters of the GAB equation of all examined modified starch samples were determined with the same high accuracy, which is proven by the low values of the sums of the squared deviations (Table 3). 
T a b l e 4. Microstructural characteristics of the tested modified maize starch

\begin{tabular}{cccc}
\hline Product & $\begin{array}{c}\text { Sorption specific surface } \\
\left(\mathrm{m}^{2} \mathrm{~g}^{-1} \mathrm{~d} . \mathrm{m} .\right)\end{array}$ & $\begin{array}{c}\text { Total capacity of capillaries } \\
\left(\mathrm{mm}^{3} 100 \mathrm{~g}^{-1} \mathrm{~d} . \mathrm{m} .\right)\end{array}$ & $\begin{array}{c}\text { Size of capillaries } \\
\text { at } a_{w}=0.60(\mathrm{~nm})\end{array}$ \\
\hline 12616 & 250.3 & 65.72 & 1.58 \\
12650 & 261.4 & 65.29 & 1.57 \\
06748 & 346.0 & 69.55 & 1.83 \\
\hline
\end{tabular}

Values of the Guggenheim energy constant $C_{G}$ ranged from 6.2 to 17.3 , which clearly indicates a physical character of surface absorption (Atkins, 2001). At the same time, the obtained values of constant $\mathrm{C}_{\mathrm{G}}$ confirm the usefulness of the GAB model to describe the gathered data sets. According to Lewicki (1997), this parameter (assuming a value higher than 5.67) indicates that the isotherm of a given product can be considered as type II.

The values of the constant correcting properties of molecules forming a multilayer in comparison to a liquid phase $\mathrm{K}$ range from 0.84 to 1.00 for a product in which proteins play a crucial role in forming sorptive properties. On the other hand, the range between 0.717 and 0.893 is typical for a product in which the fibre fraction determines the sorptive properties (Pérez-Alonso et al., 2006). The obtained results indicate that the examined starches 12616 and 12650 demonstrate sorptive properties close to those of fibre. However, starch 06748 demonstrated definitely lower values, which may suggest that the modification process had a significant effect on the sorptivity of this material.

The next part of the research was to describe the microstructural characteristics of the surface of modified starch samples based on the $v_{m}$ monolayer development determined on the basis of the GAB model and the course of adsorption isotherms as regards capillary condensation. The largest specific surface area was found for starch 06748 and the lowest for starch 12616 (Table 4). Sample 06748 was characterised by the largest total capacity of capillaries, which was positively correlated with the estimated sizes of capillaries filled after initiating capillary condensation (Table 4). The obtained results indicate that starches 12650 and 12616 were characterised by less porous surfaces of molecules, and capillaries prevailing on their surfaces were characterised by lower sizes as compared to 06748 . The obtained values were within the ranges of $0.42 \pm 0.01$ for native maize starch and $684.5 \pm 0.12$ for enzyme hydrolysed starch followed by cross-linking, specified by Guo et al . (2015) for different types of maize starch.

A parallel estimation of parameters was made by transforming the obtained results with the application of the BET model. The comparison of the sums of squared deviations indicates that this equation describes better the process of water vapour adsorption on the surface of 12616 and 12650 starch molecules than in the case of 06748 (Table 5). Although all examined samples were obtained from the same raw material (maize starch), its modification resulted in significant diversification of sorptive properties. Additionally, it should be noted that, just like the GAB equation, the BET equation also indicates significantly better development of the monomolecular layer of starch 06748 than of starches 12616 and 12650 . The BET equation indicates lower values of the $v_{m}$ parameter than the GAB model. A similar relationship between the results was obtained by Andrade et al. (2011). Additionally, a reversed relation between $v_{m}$ of starches 12616 and 12650 was found.

The study also included the estimation of parameters of three other models describing sorption isotherms. The obtained results are presented in Table 5. The Lewicki model of 1998 moderately reflected the course of sorption isotherms, although fitting the empirical data to the model was characterised in each case by a similar level (Table 5). The high error values (exceeding several times the values of estimated parameter $\mathrm{H}$ ) of parameter $\mathrm{H}$ estimation indicate a limited ability of this equation to describe the process of water vapour sorption by modified maize starch.

The Lewicki model of 2000 demonstrated a better fitting of the model to empirical data (Table 5), which is proven by low sums of the squared deviations for samples 12616 and 12650. Sample 06748 was not easily transformed, which is indicated by a high sum of squared deviations. At the same time, it can be assumed that the applied modification provided starch 06748 with such sorptive properties that were not previously found in the food product group. This indicates that the Lewicki model (2000), in spite of numerous advantages reported in the literature (Pałacha and Sitkiewicz, 2010) is characterised by limited applicability.

The last of the examined models was the Peleg model which described all of the modified starch samples very well (Table 5). This was demonstrated by a low and consistently similar level of squared deviation sums, as well as by the error values with which this parameter was estimated, which were equally low and similar in terms of values. Andrade et al. (2011) wrote that although the Peleg model is empirical, without a theoretical background, it presents the same or even better suitability than the GAB model.

The obtained sets of values for individual parameters indicated similar sorptive properties for samples 12616 and 12650 and the dissimilarity of sample 06748 , with parameters A, B and D being significantly differentiated. On 
T a b l e 5. Parameters of equations for modified maize starch

\begin{tabular}{|c|c|c|c|}
\hline \multirow{2}{*}{ Parameters } & \multicolumn{3}{|c|}{ Product } \\
\hline & 12616 & 12650 & 06748 \\
\hline \multicolumn{4}{|c|}{ BET equation } \\
\hline $\mathrm{SD}$ - sum of squared deviations & $0.599 \pm 0.447$ & $0.622 \pm 0.455$ & $2.662 \pm 0.942$ \\
\hline$v_{m}-$ water content in monolayer $\left(\mathrm{g} \mathrm{H}_{2} \mathrm{O}\left(100 \mathrm{~g}^{-1}\right.\right.$ d.m. $\left.)\right)$ & $2.660 \pm 0.607$ & $1.820 \pm 0.457$ & $7.401 \pm 2.510$ \\
\hline $\mathrm{C}$ - energy constant & $1.543 \pm 0.233$ & $1.929 \pm 0.308$ & $0.932 \pm 0.228$ \\
\hline \multicolumn{4}{|c|}{ Lewicki equation (1998) } \\
\hline SD - sum of squared deviations & $7.817 \pm 1.250$ & $10.404 \pm 1.443$ & $7.357 \pm 1.213$ \\
\hline $\mathrm{F}-$ constant & $5.444 \pm 0.769$ & $5.169 \pm 0.838$ & $8.173 \pm 0.608$ \\
\hline $\mathrm{G}-$ constant & $0.870 \pm 0.316$ & $0.909 \pm 0.364$ & $0.615 \pm 0.172$ \\
\hline $\mathrm{H}-$ constant & $-9.420 \pm 74.29$ & $-9.443 \pm 90.49$ & $-7.872 \pm 21.37$ \\
\hline \multicolumn{4}{|c|}{ Lewicki equation (2000) } \\
\hline SD - sum of squared deviations & $0.966 \pm 0.401$ & $0.897 \pm 0.387$ & $266.8 \pm 6.669$ \\
\hline A - constant & $11.807 \pm 0.138$ & $11.509 \pm 0.134$ & $13.370 \pm 2.125$ \\
\hline B - constant & $-0.452 \pm 0.012$ & $-0.469 \pm 0.011$ & $0.1 \pm 0.157$ \\
\hline \multicolumn{4}{|c|}{ Peleg equation } \\
\hline SD - sum of squared deviations & $0.292 \pm 0.270$ & $0.257 \pm 0.253$ & $0.246 \pm 0.248$ \\
\hline A - constant & $22.703 \pm 1.370$ & $21.999 \pm 1.459$ & $14.768 \pm 3.377$ \\
\hline B - constant & $3.336 \pm 0.533$ & $3.245 \pm 0.519$ & $6.405 \pm 1.500$ \\
\hline $\mathrm{D}$ - constant & $11.419 \pm 2.121$ & $11.544 \pm 2.251$ & $18.746 \pm 0.720$ \\
\hline$E-$ constant & $0.460 \pm 0.112$ & $0.523 \pm 0.115$ & $0.512 \pm 0.031$ \\
\hline
\end{tabular}

the other hand, parameter E did not show any clear differences concerning adsorptive characteristics between the examined samples.

To summarise, it should be concluded that the GAB model and the Peleg model can be regarded as models demonstrating greater universality in the description of the surface absorption of water vapour than other equations (BET, Lewicki $(1998,2000))$. Both equations were characterised by similarly low sums of squared deviations for empirical and theoretical points, regardless of sorptive properties of the examined samples, and by low and consistent values of estimation errors for this parameter. Likewise, the equation parameters were estimated with an error that was small and uniform in each case.

A clear difference between the GAB and the Peleg model is the possibility to apply the GAB equation parameters to estimate the microstructure of the surface of the examined samples, which is not the case for the Peleg equation.
Consequently, it can be assumed that the GAB equation is currently the best model for describing the process of adsorption of the food products studied.

\section{CONCLUSIONS}

1. Physical modification of maize starch has a greater influence on the adsorption properties than its chemical modification. Modifying native maize starch significantly differentiated the distribution of size and parameters of particle shape in individual samples. Particles of pre-gelatinised products were highly differentiated in terms of size, and of irregular shapes. Modification of native starch was accompanied by differentiation of adsorptive properties of individual products, which was reflected in such parameters as surface of the monomolecular layer, specific sorption area and capillary characteristics of the samples. 
2. Maize starch modifications resulted in the examined samples differing in their water content and activity. Statistically significant differences was found between the sample in the chemical modification and the two others which were pre-gelatinised. The sample in the chemical modification was characterised by the largest surface area of the monomolecular layer, larger specific surface of sorption, the largest total capacity of capillaries, and larger radius of capillaries to be filled after initiating capillary condensation.

3. The Guggenheim, Anderson and de Boer equation proved the most useful for describing determined adsorption isotherms, as it revealed a high accuracy in reflecting empirical data in comparison to the Brunauer, Emmett and Teller equation and Lewicki equations. The Guggenheim, Anderson and de Boer equation was characterised by low sums of squared deviations of empirical and theoretical points, and by low and consistent error estimation values for water vapour surface adsorption parameters.

Conflict of interest: The Authors do not declare conflict of interest.

\section{REFERENCES}

Alcázar-Alay S.C. and Meireles M.A.A., 2015. Physicochemical properties, modifications and applications of starches from different botanical sources. Food Science Technol., 35, 2.

Andrade R.D.P., Lemus R.M., and Pérez C.E.C., 2011. Models of sorption isotherms for food: uses and limitations. Vitae, Revista De La Facultad De Química Farmacéutica, 18(3), 325-334.

Ao Z., Simsek S., Zhang G., Venkatachalam M., Reuhs B.L., and Hamaker B.R., 2007. Starch with a slow digestion property produced by altering its chain length, branch density, and crystalline structure. J. Agric. Food Chem., 55, 4540-4547.

Ashogbon A.O. and Akintayo E.T., 2014. Recent trend in the physical and chemical modification of starches from different botanical sources: A review. Starch/Stärke, 66, 41-57.

Atkins P.W., 2001. Physical chemistry (in Polish). PWN, Warsaw, Poland.

Bayod E., Willers E.P., and Tornberg E., 2008. Rheological and structural characterization of tomato paste and its influence on the quality of ketchup. LWT - Food Science and Technology, 41, 1289-1300.

Builders P.F. and Arhewoh M.I., 2016. Pharmaceutical applications of native starch in conventional drug delivery. Starch/ Stärke, 68, 864-873.

Che L.-M., Li D., Wang L.-J., Chen X.D., and Mao Z.-H., 2007. Micronization and hydrophobic modification of cassava starch. Int. J. Food Prop., 10, 527-536.

Dąbrowski A., 2001. Adsorption - from theory to practice. Advances Colloid Interface Sci., 93, 135-224.

Figura L.O. and Teixeira A.A., 2007. Food physics. Physical Properties - Measurement and Applications. SpringerVerlag Berlin-Heidelberg.

Fox P.F. and McSweeney P.L.H., 2003. Advanced dairy chemistry. Springer Science+Business Media, New York, USA.
Fuglie K.O., 2004. Challenging Bennet's law: the new economics of starchy staples in Asia. Food Policy, 29(2), 184-202.

Gal S., 1983. The need for, and practical applications of sorption data. In: Physical Properties of Foods (Eds Jowitt R., Escher F., Hällström B., Meffert H.F.T., Spiess W.E.L., Vos G.). Applied Science Published, New York, USA

Guo L., Liu R., Li X., Sun Y., and Du X., 2015. The physical and adsorption properties of different modified corn starches. Starch/Stärke, 67, 237-246.

Han Z., Zeng X., Zhang B., and Yu S., 2009. Effect of pulsed electric fields (PEF) treatment on the properties of corn starch. J. Food Eng., 93, 318-323.

Hebelstrup K.H., Sagnelli D., and Blennow A., 2015. The future of starch bioengineering: GM microorganisms or GM plants? Frontiers in Plant Science, 6, 247

Hirsch J.B. and Kokini J.I., 2002. Understanding the mechanism of cross-linking agents (POCI3, STMP, EPT) through swelling behavior and pasting properties of cross-linked waxy maize starches. Cereal Chem., 79, 102-107.

Huang Z.-Q., Lu J.-P., Li X.-H., and Tong Z.F., 2007. Effect of mechanical activation on physicochemical properties and structure of cassava starch. Carbohydr. Polym., 68, $128-135$

Jobling S., 2004. Improving starch for food and industrial applications. Current Opinion in Plant Biology, 7: 210-218.

Juszczak L., Oczadły Z., and Galkowska D., 2013. Effect of modified starches on rheological properties of ketchup. Food Bioprocess Technol., 6, 5, 1251-1260.

Kosseva M.R. and Webb C., (Eds) 2013. Food Industry Wastes. Assessment and recuperation of commodities. Food Science and Technology. International Series.

Lee S.-J., Hong J.Y., Lee E.-J., Chung H.-J., and Lim S.-T., 2015. Impact of single and dual modifications on physicochemical properties of japonica and indica rice starches. Carbohydrate Polymers, 122, 77-83.

Leszczyński W., 2004. Resistant starch - classification, structure, production. Polish J. Food Nutrition Sci., 13/54, 37-50.

Lewandowicz G. and Soral-Śmietana M., 2004. Starch modification by iterated syneresis. Carbohydr. Polym., 56, 403-413.

Lewicki P.P., 1997. The applicability of the GAB model to food water sorption isotherms. Int. J. Food Sci. Technol., 32, 553-557.

Lewicki P.P., 1998. A three parameter equation for food moisture sorption isotherms. J. Food Process Eng., 21(2), 127-144.

Lewicki P.P., 2000. Raoult's law based food water sorption isotherm. J. Food Process Eng., 43, 31-40.

Lim S.T., Han J.-A., Lim H.S., and BeMiller J.N., 2002. Modification of starch by dry heating with ionic gums. Cereal Chem., 79, 601-606.

Neelam K., Vijay S., and Lalit S., 2012. Various techniques for the modification of starch and the applications of its derivatives. Int. Research J. Pharmacy, 3 (5), 25-31.

Nemtanu M.R. and Minea R., 2006. Functional properties of corn starch treated with corona electrical discharges. Macromol. Symp., 245-246, 525-528.

Ocieczek A., 2010. Comparing the sorptive properties of selected brands of instant coffee - a short report. Polish J. Food. Nutrition Sci., 60(3), 261-264. 
Ocieczek A. and Kostek R., 2009. Sorptive properties of type 2000 wheat and rye flours. Acta Agrophysica, 14(2), 393-402.

Paderewski M., 1999. Adsorption processes in chemical engineering (in Polish). WNT, Warsaw, Poland.

Palacha Z. and Sitkiewicz I., 2010. The physical properties of the food (in Polish). WNT, Warsaw, Poland.

Pérez-Alonso C., Berstain C.I., Lobato-Calleros C., RodríguezHuezo M.E., and Vernon-Carter E.J., 2006. Thermodynamic analysis of the sorption isotherms of pure and blended carbohydrate polymers. J. Food Eng., 77, 753-760.

Pkkahuta C., Shobsnggobi S., and Varavimit S., 2007. Effect of osmotic pressure on starch : New method of physical modification of starch. Starch/Stärke, 58, 78-90.

PN-ISO 712:2012. Cereal grains and cereal preparations Determination of moisture - Appeal method.

Skic K. and Sokołowska Z., 2015. Water vapour sorption on mixtures of podzolic soils with organic fertilizer rosahumus. Acta Agrophysica, 22(3), 301-310.

Singh N., Singh J., Kaur R., Sodhi N.S., and Gill B.S., 2003. Morphological, thermal and rheological properties of starches from different botanical sources. Food Chemistry, 81: 219-231.
Stasiak M., Molenda M., Opaliński I., and Blaszczak W., 2013. Mechanical properties of native maize, wheat, and potato starches. Czech J. Food Sci., 31, 4, 347-354.

Steeneken P.A.M. and Woortman A.J.J., 2009. Superheated starch: A novel approach towards spreadable particle gels. Food Hydrocolloids, 23, 394-405.

Szymońska J., Krok F., Komorowska-Czepirska E., and Rebilas K., 2003. Modification of granular potato starch by multiple deep-freezing and thawing. Carbohydr. Polym., 52, $1-10$.

Tharanathan R.N., 2005. Starch - value addition by modification. Critical Reviews in Food Science and Nutrition, 45, 5, 371-384.

Visakh P.M., 2015. Starch: State-of-the-Art, New Challenges and Opportunities, 1-16, In: Starch-based Blends, Composites and Nanocomposites (Eds Visakh P.M., Long Yu). Royal Society of Chemistry, Cambridge, UK.

Wang Y.-J. and Wang L., 2002. Characterization of acetylated waxy maize starches prepared under catalysis by different alkali and alkaline-earth hydroxides. Starch/Stärke, 54, 25-30.

Zarguili I., Maache-Rezzoug Z., Loisel C., and Doublier J.-L., 2006. Influence of DIC hydrothermal process conditions on the gelatinization properties of standard maize starch. J. Food Eng., 77, 454-461. 